\section{Reducing the back overuse-related risks in alpine ski racing: let's put research into sports practice}

\author{
Jörg Spörri, ${ }^{1}$ Josef Kröll, ${ }^{2}$ Matej Supej, ${ }^{3}$ Erich Müller ${ }^{2}$
}

It is well recognised in alpine ski racing (ASR) that the risk of traumatic injuries is high. ${ }^{1}$ Yet, so far the nature and causation of ASR-related back overuse injuries have received little attention. ${ }^{2}$ During adolescence, competitive alpine skiers are already suffering from more prevalent spinal disc degeneration and more severe back pain than age-matched controls. ${ }^{3}$ Factors previously suggested as being important components of mechanisms leading to overuse injuries of the back are: (1) adverse trunk kinematics including a combined occurrence of frontal bending, lateral bending and torsion, ${ }^{4}$ (2) high ground reaction forces, ${ }^{4}$ and (3) excessive exposure to low-frequency whole-body vibrations (WBV) $(\sim 4-10 \mathrm{~Hz}$; ie, frequencies close to resonant frequency of the spine; known to be the most damaging to spinal structures). ${ }^{5}$ All of these factors have been demonstrated to be inherent parts of ASR and occur in different combinations and intensities. ${ }^{45}$ Despite applying quite radical equipment and course modifications, previous studies discovered the ASR-specific overall trunk kinematics to be unchangeable. ${ }^{78}$

\section{LOW-FREQUENCY WBV IN COMBINATION WITH HIGH GROUND REACTION FORCES: AN OVERLOOKED RISK FACTOR?}

Regarding low-frequency WBV exposure in combination with high ground reaction forces, recent studies revealed significant differences in the power spectral density (ie, the signal's power distribution over frequency) and the root mean square of low-frequency weighted vibrations $\left(R M S_{\text {ISO }}\right.$ ie, acceleration data filtered according to the international standard ISO 2631) between different alpine skiing techniques and ASR competition disciplines. ${ }^{5}$ The extent of the skis skidding sideways was discovered to be associated with the occurring WBV $(\sim 8-35 \mathrm{~Hz})$ and acting forces. ${ }^{6}$ In many skiing situations, the WBV exposure massively exceeded the limits set by the European Directive 2002/44/EC for health and safety. ${ }^{6}$ Moreover, in ASR, acting ground reaction forces can reach up to 2.89 times body weight. ${ }^{4}$ Accordingly, any measure generally reducing the WBV exposure and/or the ground reaction forces while skiing should be applied. ${ }^{56}$

More specifically, one could hypothesise that measures affecting the ski-snow interaction might be helpful for reducing the low-frequency WBV and acting ground reaction forces; thus, minimising athletes' overall load exposures. As an exemplary measure for affecting the skisnow interaction, and thereby influencing the low-frequency vibrations that act on the skiers' spines, different 'snow preparation techniques' are further elaborated hereinafter.

\section{PUTTING RESEARCH INTO SPORTS \\ PRACTICE: 'SNOW PREPARATION TECHNIQUES' AS A PREVENTION MEASURE FOR OVERUSE INJURIES OF THE BACK IN ASR?}

During a biomechanical field experiment in slalom, the differences in WBV exposure and ground reaction forces (ie, representing the overall mechanical load) between a well-packed, machine-groomed artificial snow surface and the same preparation procedure in combination with high-pressure water injection (performed with a World Cup ASR typical injection bar system) were compared. Methods are further described in online supplementary box 1 .

When skiing on the water-injected slalom course, the $R M S_{\text {Iso }}$ value (ie, the exposure to vibrations acting on the

\footnotetext{
'Department of Orthopaedics, Balgrist University Hospital, University of Zurich, Zurich, Switzerland ${ }^{2}$ Department of Sport Science and Kinesiology, University of Salzburg, Hallein-Rif, Austria ${ }^{3}$ Faculty of Sport, University of Ljubljana, Ljubljana, Slovenia

Correspondence to PD Dr. Jörg Spörri, Department of Orthopaedics, Balgrist University Hospital, University of Zurich, Forchstrasse 340, 8008 Zurich, Switzerland; joerg.spoerri@balgrist.ch
} 
spine) was $5.7 \%$ higher than on the course that was machine groomed only (table 1). The average ground reaction forces were found to be unaffectedly high on both courses.

In view of these findings, and knowing that in ASR short-term WBV (shocks), particularly in combination with high ground reaction forces, can result in even more adverse loading conditions/ higher health risks, the application of water injection in addition to a superior machine-groomed preparation should be reconsidered, and a standardisation by international competition rules should be discussed. Special care should be applied during training and competitions of youth athletes on such snow conditions, since their bodies are in stages of maturation and, therefore, especially sensitive to an accumulation of the adverse spinal loading. Moreover, as a result of less developed skills, younger athletes may skid more sideways when skiing on water-injected slopes; a factor known to increase the WBV exposure even further. ${ }^{6}$ Finally, omitting or restricting water-injected slopes could induce the ski industry to construct less aggressive skis and ski boots, which might be beneficial for the purpose of injury prevention, in general. ${ }^{1}$

\section{WHERE TO GO FROM HERE?}

Future research on back overuse injuries in ASR should focus more specifically on low-frequency WBV in combination with high ground reaction forces, as these are most likely the only two variables that can be modified by external prevention measures. ${ }^{578}$ As illustrated in this study, one such measure might be found in 'snow preparation techniques' and corresponding safety regulations. Turning research into action could mean: (1) in (youth) ASR, additional water injection should only be used with care, or (2) if the actual snow conditions are for any reason demanding (eg, introduce a higher amount of skidding and, therefore, higher WBV exposure ${ }^{6}$ ), one should reduce the number of skiing days, or at least the number of runs per skiing day under such conditions. In the future, body-worn sensor technology might help generate a more profound understanding of the doseeffect relation of low-frequency WBV and force exposure, and to keep ASR-related training loads at a healthy level.

Acknowledgements The authors thank Dr Benedikt Fasel and Professor Kamiar Aminian from the Laboratory of Movement Analysis and Measurement at the École Polytechnique Fédéralede Lausanne for their support in collecting and/or evaluating the new experimental data.

Contributors IS designed and conceptualised the paper. JS and JK collected the new experimental data. JS wrote the first draft of the paper. All authors contributed to the manuscript and approved the final version.

Funding This study was financially supported by the International Ski Federation (FIS) Injury Surveillance System (ISS).

\section{Competing interests None declared.}

Patient consent Not required.

Ethics approval Ethics committee of the Department of Sport Science and Kinesiology at the University of Salzburg.

Provenance and peer review Not commissioned; internally peer reviewed.

\section{(1)

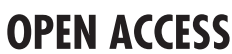

Open access This is an open access article distributed in accordance with the Creative Commons Attribution Non Commercial (CC BY-NC 4.0) license, which permits others to distribute, remix, adapt, build upon this work non-commercially, and license their derivative works on different terms, provided the original work is properly cited, appropriate credit is given, any changes made indicated, and the use is non-commercial. See: http://creativecommons.org/ licenses/by-nc/4.0/

(C) Author(s) (or their employer(s)) 2019. Re-use permitted under CC BY-NC. No commercial re-use. See rights and permissions. Published by BMJ.

- Additional material is published online only. To view please visit the journal online (http://dx.doi.org/ 10.1136/bjsports-2018-100040).

\section{Check for updates}

To cite Spörri J, Kröll J, Supej M, et al. Br J Sports Med 2019;53:2-3.

Accepted 2 October 2018

Published Online First 15 October 2018

Br J Sports Med 2019;53:2-3.

doi:10.1136/bjsports-2018-100040

\section{REFERENCES}

1 Spörri J, Kröll J, Gilgien M, et al. How to prevent injuries in alpine ski racing: what do we know and where do we go from here? Sports Med 2017;47:599-614.

2 Supej M, Senner V, Petrone N, et al. Reducing the risks for traumatic and overuse injury among competitive alpine skiers. Br J Sports Med 2017;51:1-2.

3 Witwit WA, Kovac P, Sward A, et al. Disc degeneration on MRI is more prevalent in young elite skiers compared to controls. Knee Surg Sports Traumatol Arthrosc 2018;26:325-32.

4 Spörri J, Kröll J, Haid C, et al. Potential mechanisms leading to overuse injuries of the back in alpine ski racing: a descriptive biomechanical study. Am J Sports Med 2015;43:2042-8.

5 Spörri J, Kröll J, Fasel B, et al. The use of body worn sensors for detecting the vibrations acting on the lower back in alpine ski racing. Front Physiol 2017:8:522.

6 Supej M, Ogrin J, Holmberg HC. Whole-body vibrations associated with alpine skiing: a risk factor for low back pain? Front Physiol 2018;9:204.

7 Spörri J, Kröll J, Fasel B, et al. Course setting as a prevention measure for overuse injuries of the back in alpine ski racing: a kinematic and kinetic study of giant slalom and slalom. Orthop I Sports Med 2016:4:2325967116630719.

8 Spörri J, Kröll J, Fasel B, et al. Standing height as a prevention measure for overuse injuries of the back in alpine ski racing: a kinematic and kinetic study of giant slalom. Orthop I Sports Med 2018;6:2325967117747843. 